\title{
FATIGUE AND HYDROGEN CRACKING IN CANNONS WITH MECHANICAL AND THERMAL RESIDUAL STRESSES
}

\author{
J. H. Underwood ${ }^{1}$, A. P. Parker $^{2}$, E. Troiano ${ }^{1}$, G. N. Vigilante ${ }^{1}$, M. D. Witherell ${ }^{1}$ \\ ${ }^{1}$ Army Armament Research, Development and Engineering Center, Watervliet, NY 12189 USA \\ ${ }^{2}$ Royal Military College of Science, Cranfield University, Swindon SN6 8LA UK
}

\begin{abstract}
Bauschinger-modified autofrettage residual stresses are used to improve the fatigue intensity factor model for fatigue life of cannon pressure vessels. Effects of yield strength and initial crack size are included with applied and residual stress in a S-N description of cannon tube life that matches full-scale cannon fatigue test results with a $\mathrm{R}^{2}$ correlation of 0.92 . Thermally induced residual stress near the bore of a fired cannon is modeled by finite difference calculations of temperature and mechanics calculations of transient thermal stress and resulting residual stress. Temperature dependent thermal and physical properties are used, and the temperature distributions are validated by direct comparison with the known temperatures and the observed depths of microstructural damage and transformation in fired cannons. Calculations of fatigue life and yield pressure for a range of applied pressure, diameter ratio, yield strength and \% autofrettage agree well with measurements from full-scale cannons. Increased life is predicted for increases in yield strength and \% autofrettage, although the Bauschinger effect significantly reduces the amount of life increase for autofrettage above $50 \%$. The combined effects of mechanically induced residual stress and thermally induced residual stress on cannon fatigue life are calculated, using an increased initial crack size to account for thermal residual stress. Calculations of fatigue life are presented for a range of applied pressure and for selected gas temperatures.
\end{abstract}

KEY WORDS: metal fatigue, pressure vessels, autofrettage, thermal stress, high strength steels, hydrogen crack

\section{INTRODUCTION}

The benefit of mechanically induced autofrettage residual stress in extending the fatigue life of a pressure vessel has been known for decades. Only relatively recently has comprehensive predictive analysis of autofrettage residual stress been available that can account for the actual material properties of pressure vessel steels, most importantly the significant reduction of compressive yield strength that occurs in an autofrettaged vessel, known as the Bauschinger effect. Measurements of the Bauschinger effect in the Ni-Cr-Mo steels commonly used in cannon pressure vessels have long been available [1]. Analysis of the Bauschinger strength reductions that are observed for different vessel diameter ratios and degrees of autofrettage was described by Chaaban et al [2], but they used a simple bilinear representation of the reduced compressive yielding, whereas a much more complex non-linear behavior is observed. Parker [3] has provided useful expressions that will be used here to calculate autofrettage residual stresses at the bore of pressure vessels with Ni-Cr-Mo type Bauschinger properties, accounting for diameter ratio, degree of autofrettage and non-linear behavior, the effects of concern here.

In the past decade a troublesome type of thermally induced residual stress has been found to affect cracking and service life of cannon pressure vessels. Underwood et al [4] showed metallographic evidence of a constantdepth array of cracks at the inner surface of fired cannon tubes that cannot be explained by a mechanical fatigue process. Finite difference calculations of the transient temperatures at the inner surface of a fired cannon tube predicted yield-level transient compressive stresses to about the same depth as the crack array, suggesting that tensile residual stress was present to this depth. Given that significant hydrogen is produced in cannon firing and cannon steels are highly susceptible to hydrogen cracking, the constant-depth cracks can be explained as 
hydrogen cracks. In the work here additional finite difference temperature calculations and transient and residual stress calculations are performed, to determine the effect of thermally induced residual stresses and cracking on fatigue life of cannon pressure vessels. The fatigue life implications of both the mechanically induced autofrettage residual stresses and the thermally induced firing residual stresses will be described in the work here using the fatigue intensity factor (FIF) concept developed by Underwood and Parker [5]. This modified S-N approach gives a high correlation, single-expression description of fatigue life for a wide range of vessel configuration, stress concentration, applied and residual stresses, yield strength and initial crack size.

\section{ANALYSIS}

The residual stresses in a cannon pressure vessel that will be discussed here are those produced by a mechanical mandrel-swage autofrettage process during fabrication of the cannon tube and those produced by the transient convective heating of the inner surface (ID) of the tube during cannon firing. Transient heating of a cannon ID during firing has traditionally been important only because it would initiate fatigue cracking somewhat earlier than would otherwise be expected. However, with increases in cannon firing pressures, temperatures and duration, ID thermal damage is deeper and asserts a more significant control over cannon fatigue life than in the past. The finite difference method is used to calculate the near-ID transient temperature distribution, as the initial measure of the degree and depth of thermal damage. The temperatures are then used to calculate the biaxial transient compressive stresses and the tensile residual stresses in the locations of the steel substrate where the compressive stresses exceed the yield strength. The depth of a significant tensile residual stress is taken as the important final measure of thermal firing damage, because hydrogen cracking is expected to occur to this depth in the steel and thereby accelerate the fatigue failure process.

\section{Autofrettage Residual Stresses and Yielding}

The familiar Tresca-plane stress expressions for hoop residual stress in an autofrettaged tube were modified [3] to apply to the Mises-open end conditions that are more appropriate for cannon pressure vessels and also to include the effect of the Bauschinger reduced strength. These modified expressions are:

$$
\begin{aligned}
& \mathrm{S}_{\theta \mathrm{R}}=\mathrm{R}_{\mathrm{S}}\left[-\mathrm{p}_{\mathrm{Y}}+\mathrm{S}_{\mathrm{Y}}[1+\ln (\mathrm{r} / \mathrm{a})]-\mathrm{p}_{\mathrm{Y}} \mathrm{a}^{2}\left(\mathrm{~b}^{2}-\mathrm{a}^{2}\right)\left(1+\mathrm{b}^{2} / \mathrm{r}^{2}\right)\right] \quad \text { for: } a<r<r_{Y} \\
& \mathrm{p}_{\mathrm{Y}}=\mathrm{R}_{\mathrm{P}}\left[\mathrm{S}_{\mathrm{Y}}\left[\ln \left(\mathrm{r}_{\mathrm{Y}} / \mathrm{a}\right)+\left(\mathrm{b}^{2}-\mathrm{r}_{\mathrm{Y}}^{2}\right) / 2 \mathrm{~b}^{2}\right]\right]
\end{aligned}
$$

where $a$ and $b$ are the inner and outer tube radii, $r_{Y}$ is the autofrettage radius, $S_{Y}$ is yield strength, $p_{Y}$ is the equivalent pressure that would be required to accomplish the mandrel autofrettage, and $\mathrm{R}_{\mathrm{S}}$ and $\mathrm{R}_{\mathrm{P}}$ are the ratios that accomplish the modification for various degrees of autofrettage, $n$. At the critical ID, i.e., at $r=a$ :

$$
\begin{aligned}
& \mathrm{R}_{\mathrm{S}}=1.669-0.165(\mathrm{~b} / \mathrm{a})-0.730 \mathrm{n}^{3}+1.984 \mathrm{n}^{2}-1.887 \mathrm{n} \quad \text { for: } 1.75<b / a<3.00 ; \quad 30 \%<n<80 \% \\
& \mathrm{R}_{\mathrm{P}}=1.155 /\left[1+1 / 3(\mathrm{~b} / \mathrm{a})^{4-2.3 \mathrm{n}}\right]^{1 / 2} \quad \text { for: } n<70 \%
\end{aligned}
$$

Equations 1-4 are used here to calculate the mechanically induced hoop residual stresses at the ID of autofrettaged tubes, including the important effect of the Bauschinger reduced strength for the type of Ni-Cr-Mo steels used in cannons. Once the Bauschinger-modified hoop residual stresses are known, the Bauschingeraffected pressure, $\mathrm{p}^{*}$, at which the cannon tube re-yields when re-pressurized following initial autofrettage can be determined, using the Mises criterion in the notation here:

$$
\mathrm{S}_{\mathrm{Y}}=\left[\left[\left(\mathrm{S}_{\theta \mathrm{T}}-\mathrm{p}^{*}\right)^{2}+\left(\mathrm{p}^{*}-v \mathrm{~S}_{\theta \mathrm{R}}\right)^{2}+\left(v \mathrm{~S}_{\theta \mathrm{R}}-\mathrm{S}_{\theta \mathrm{T}}\right)^{2}\right] / 2^{1 / 2}\right]^{1 / 2} \quad \text { for } r=a
$$

where $S_{\theta \mathrm{T}}$ is total hoop stress (sum of applied and residual) and $v \mathrm{~S}_{\theta \mathrm{R}}$ is an estimate of axial residual stress [3]. Equation 5 gives a Bauschinger-modified ID yield pressure, but it does not include any effect of additional reyielding discussed by Parker [3] that can occur near the yield pressure. This will be considered in future work.

\section{Transient Temperatures and Thermal Residual Stresses}

Finite difference calculations of one-dimensional convective heat flow were used to determine the near-ID temperatures produced by cannon firing conditions. The calculations used increments of $0.02 \mathrm{~mm}$ in depth below the heated bore surface. About fifty increments were required for the temperature to drop from typically 
$1500{ }^{\circ} \mathrm{K}$ at the surface to within $1^{\circ} \mathrm{K}$ of ambient $\left(300^{\circ} \mathrm{K}\right)$ at about $1 \mathrm{~mm}$ below the surface, for the few ms of convective heating typical of cannon firing. Temperature dependent material properties [6-8] of the $0.1 \mathrm{~mm}$ thick electro-plated chromium bore coating and the Ni-Cr-Mo steel substrate were used for the analysis, in the form $\delta(T)=C_{0}+C_{1} T$, with values of $C_{0}$ and $C_{1}$ as in Table 1 . The inputs to the finite difference calculations, in addition to the chromium and steel properties, were: the initial ambient temperature, $\mathrm{T}_{\mathrm{i}}, 300{ }^{\circ} \mathrm{K}$; the duration of the convective heating pulse at the tube surface, $0.008 \mathrm{~s}$; the convection coefficient, $\mathrm{h}$, of the heating pulse, $193,000 \mathrm{~W} / \mathrm{m}^{2} \mathrm{~K}$; and the mean gas temperature of the pulse, with values as discussed in the upcoming results.

\section{TABLE 1 - TEMPERATURE DEPENDENT PROPERTIES OF CHROMIUM AND STEEL}

\begin{tabular}{lllllll}
\multicolumn{1}{c}{} & \multicolumn{2}{c}{ Chromium } & \multicolumn{2}{c}{ Ni-Cr-Mo Steel } \\
property & units & range; ${ }^{\circ} \mathrm{K}$ & $\mathrm{C}_{0}$ & $\mathrm{C}_{1}$ & $\mathrm{C}_{0}$ & $\mathrm{C}_{1}$ \\
\hline thermal diffusivity, $\delta$ & $\mathrm{m}^{2} / \mathrm{s}$ & $300-2000$ & $29.6 \mathrm{E}-6$ & $-12.6 \mathrm{E}-9$ & $11.7 \mathrm{E}-6$ & $-5.3 \mathrm{E}-9$ \\
thermal conductivity, $\mathrm{k}$ & $\mathrm{W} / \mathrm{m}{ }^{\circ} \mathrm{K}$ & $300-2000$ & 97.2 & -0.0266 & 43.6 & -0.0097 \\
elastic modulus, $\mathrm{E}$ & $\mathrm{GPa}$ & $300-1000$ & -- & -- & 248 & -0.0968 \\
thermal expansion, $\alpha$ & $1 /{ }^{\circ} \mathrm{K}$ & $300-1000$ & -- & -- & $13.5 \mathrm{E}-6$ & 0 \\
yield strength, $\mathrm{S}_{\mathrm{Y}}$ & $\mathrm{MPa}$ & $300-1000$ & -- & -- & 1740 & -1.62 \\
\hline
\end{tabular}

Expressions for the near-bore, transient, in-plane, biaxial compressive thermal stress, $\mathrm{S}_{\mathrm{T}}$, and the tensile residual stress, $\mathrm{S}_{\mathrm{R}}$, produced when the transient stress exceeds the material yield strength are:

$\mathrm{S}_{\mathrm{T}}=-\mathrm{E} \alpha\left[\mathrm{T}\{\mathrm{x}, \mathrm{t}\}-\mathrm{T}_{\mathrm{i}}\right] /[1-v]$

where $v$ is Poisson's ratio; the transient temperature, $\mathrm{T}$ is for a given depth, $\mathrm{x}$ below the bore surface and time, $\mathrm{t}$ after the start of a heating pulse; the term $[1-v]$ accounts for the biaxial nature of the temperature and stress distributions. Then $S_{R}$ is determined directly using the linear unloading concept: $S_{R}=-S_{T}-S_{Y}$.

\section{Fatigue Intensity Factor versus Life}

The effects of autofrettage and thermal residual stresses on fatigue life will be described in the work here using the fatigue intensity factor (FIF) concept [5]. In brief summary, the FIF concept adds a quantitative measure of material yield strength and initial crack size to the stress parameter in a $\log$ stress vs $\log \operatorname{life}$ description of fatigue life behavior of a structure. By adding material strength and initial crack size to S-N life descriptions, significant improvements in life modeling of cannon pressure vessels have been shown. The key expressions for an FIF description of ID-initiated fatigue life of a pressurized, autofrettaged cannon pressure vessel are:

fatigue intensity factor $=\Delta \mathrm{S}_{\mathrm{LOCAL}} \times\left(\mathrm{S}_{\mathrm{Y}-\mathrm{NOM}} / \mathrm{S}_{\mathrm{Y}}\right) \times\left(\mathrm{a}_{\mathrm{i}} / \mathrm{a}_{\mathrm{i}-\mathrm{NOM}}\right)^{1 / 6}$

$\Delta \mathrm{S}_{\mathrm{LOCAL}}=\mathrm{k}_{\mathrm{t}} \mathrm{S}_{\mathrm{APPLIED}}+\mathrm{S}_{\mathrm{RESIDUAL}}+\mathrm{p}$

Note that the local stress range for ID-initiated cracking includes: the familiar Lamé applied ID stress for the appropriate $\mathrm{p}$ and $\mathrm{b} / \mathrm{a}$, with stress concentration factor, $\mathrm{k}_{\mathrm{t}}$ if one is present; the ID hoop residual stress, accounting for the Bauschinger reduced strength, using Eqs. 1-4, but no $k_{t}$ even if present because it would be negated by the Bauschinger effect; and an added stress equal in magnitude to $p$, to account for the effects of pressure on the crack faces [5]. The second term in Eq. 7 accounts for the yield strength of a given vessel, when different from the nominal yield strength of the vessels under comparison. The third term accounts for the initial crack size of a given vessel, if different from the nominal initial crack size of the vessels under comparison. As will be seen in the forthcoming results, the effect of thermally induced tensile residual stresses in cannon vessels can be accounted for by using $a_{i}$ values associated with the depth of the tensile residual stresses in cannons critically subject to hydrogen cracking.

\section{RESULTS}

\section{Mechanical Residual Stress Effects on Fatigue Life}

A baseline description of the effect of mechanical autofrettage residual stresses on ID initiated fatigue life for cannon tubes is available from prior results of full-scale cannon fatigue tests [5]. Four groups of the prior fatigue tests that were ID initiated and had well documented initial crack sizes will be used for a baseline fatigue life, see Table 2. Two of the groups were rifled cannons, with a $\mathrm{k}_{\mathrm{t}}$ of 1.7 to account for the radius 
TABLE 2 - CANNON PRESSURE VESSEL FATIGUE LIFE TESTS WITH INITIATION AT THE ID

\begin{tabular}{|c|c|c|c|c|c|c|c|}
\hline group & $\frac{\text { mean yield }}{\frac{\text { strength }}{\mathrm{S}_{\mathrm{Y}} ; \mathrm{MPa}}}$ & $\frac{\frac{\text { inner }}{\text { radius }}}{\mathrm{a} ; \mathrm{mm}}$ & $\frac{\frac{\text { outer }}{\text { radius }}}{\mathrm{b} ; \mathrm{mm}}$ & $\frac{\frac{\text { initial }}{\text { crack }}}{\mathrm{a}_{\mathrm{i}} ; \mathrm{mm}}$ & $\frac{\frac{\underline{\text { stress }}}{\text { concentration }}}{\mathrm{k}_{\mathrm{t}} ;--}$ & $\frac{\frac{\text { fatigue }}{\text { pressure }}}{\mathrm{p} ; \mathrm{MPa}}$ & $\frac{\frac{\text { degree of }}{\text { autofrettage }}}{\mathrm{n} ; \%}$ \\
\hline $75 \mathrm{~N}$ & 1280 & 89 & 187 & 0.01 & 1.7 & 345 & 0 \\
\hline $75 \mathrm{~A}$ & 1020 & 89 & 187 & 0.01 & 1.7 & 345 & 50 \\
\hline 55 & 1230 & 89 & 142 & 0.10 & 1.0 & 393 & 60 \\
\hline 20 & 1120 & 79 & 155 & 0.10 & 1.0 & 670 & 60 \\
\hline
\end{tabular}

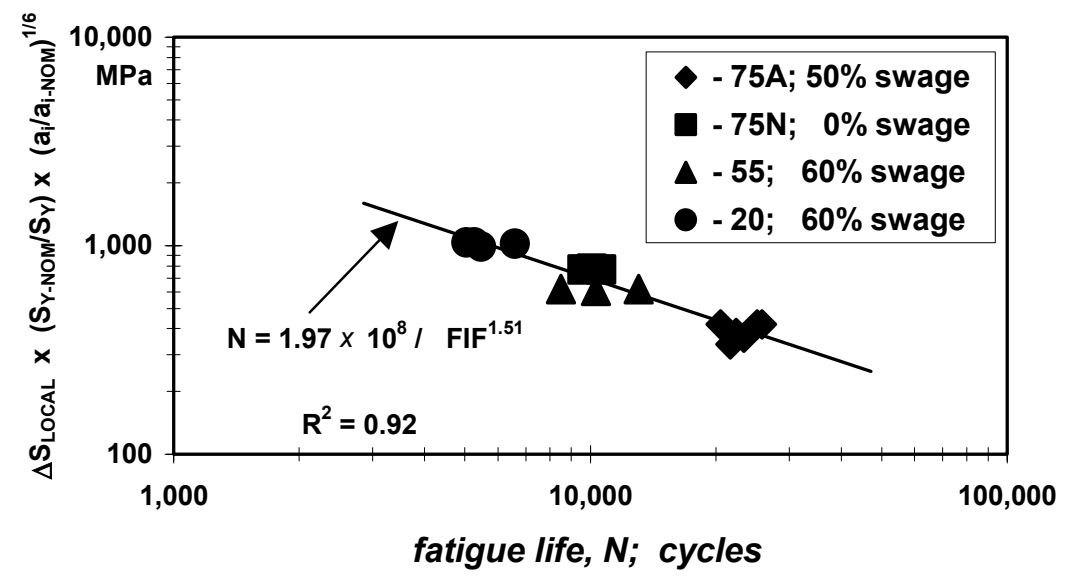

Figure 1: Lives for vessels with various \% autofrettage between the rifling land and groove. The measured fatigue lives of the sixteen tests from these four groups are shown in Fig. 1, using FIF as the stress parameter in the S-N plot. Referring again to Eqs. 7 and 8, FIF was calculated using: each of the sixteen values of $\mathrm{S}_{\mathrm{Y}} ; \mathrm{S}_{\mathrm{Y}-\mathrm{NOM}}=1134 \mathrm{MPa} ; \mathrm{a}_{\mathrm{i}-\mathrm{NOM}}=0.10 \mathrm{~mm}$; and values from Table 2 . The high correlation of the linear regression expression shows that an FIF based S-N plot gives a good description of fatigue life for cannons, including the significant effect of autofrettage residual stress.

\section{Thermal Residual Stress Verified from Thermal Damage}

Inputs to finite difference calculations of near-bore cannon temperatures are, inevitably, somewhat uncertain. So, before the calculated temperatures are used to determine residual stress, they should be verified by metallographic observations of thermal damage. This has been done for a cannon after the firing of about 40 high temperature rounds [4], see Table 3. About two thirds of the $0.12 \mathrm{~mm}$ thickness of chrome showed a transformed microstructure associated with a temperature of about $1320 \mathrm{~K}$. A more certain validation point is

\begin{tabular}{|c|c|c|c|}
\hline$\frac{\text { thickness of }}{\text { chromium layer }}$ & $\begin{array}{l}\text { TABLE } 3 \text { - SUMMAR } \\
\frac{\text { depth of chromium }}{\text { damage layer }}\end{array}$ & $\begin{array}{l}\text { F DAMAGE IN A } \\
\text { depth of steel } \\
\text { transformation } \\
\end{array}$ & $\begin{array}{l}\text { CANNON } \\
\text { depth of crack array; } \\
\text { longitudinal section }\end{array}$ \\
\hline $0.12 \mathrm{~mm}$ & $0.08 \mathrm{~mm}$ & $0.19 \mathrm{~mm}$ & $0.46 \mathrm{~mm}$ \\
\hline
\end{tabular}

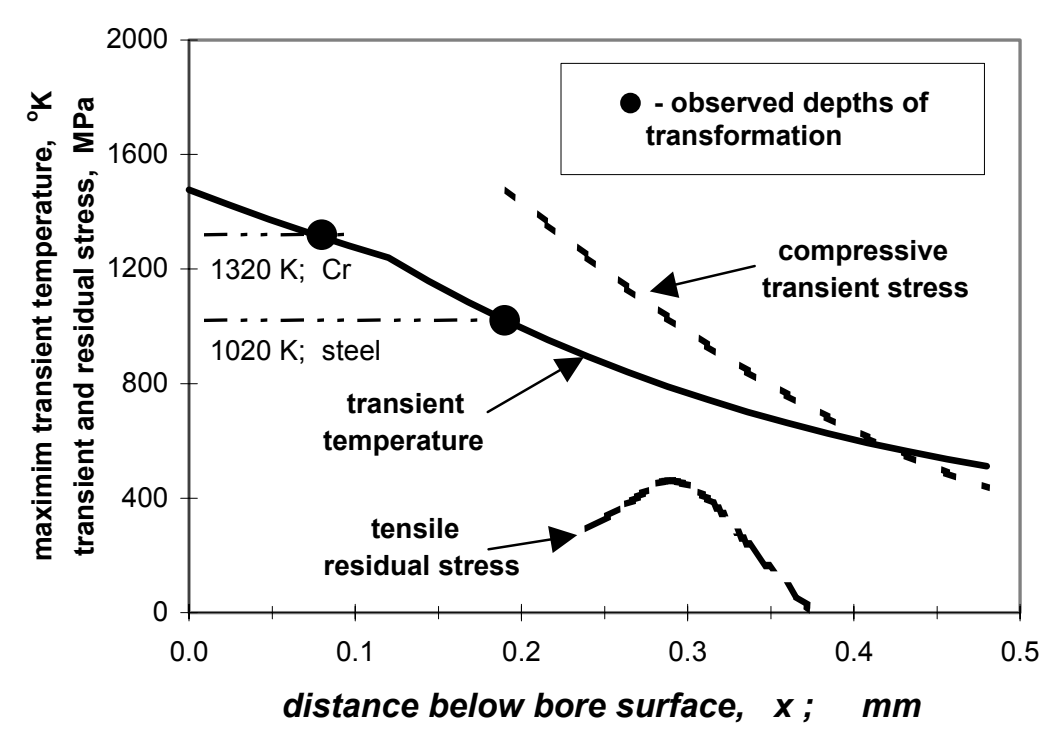

Figure 2: Firing temperatures and resultant stresses the well-known $1020 \mathrm{~K}$ phase transformation for this type of low alloy Ni-Cr-Mo cannon steel, and metallographs show a consistent, clear depth of $0.19 \mathrm{~mm}$. One further dominant damage feature observed was an ever-present array of constant depth cracks normal to the longitudinal orientation of the cannon, an orientation known to have no significant applied tensile stress. As discussed next, the crack array provides added verification of the calculated depth of thermally induced residual stress due to cannon firing.

Results of finite difference calculations of temperatures and solid mechanics calculations of transient and residual stresses, using the methods and validation already discussed, are shown in Fig. 2. The solid line shows the calculated maximum temperatures vs distance 
below the bore surface, for the following input values: the $\delta$ and $\mathrm{k}$ properties for chromium and steel from Table $1 ; \mathrm{T}_{\text {gas }}=2160 \mathrm{~K}$ and $0.008 \mathrm{~s}$ pulse duration; and $\mathrm{h}=193,000 \mathrm{~W} / \mathrm{m}^{2}{ }^{\circ} \mathrm{K}$. Note that the depths and temperatures of the $1320 \mathrm{~K}$ and $1020 \mathrm{~K}$ transformations of chromium and steel are well matched for the calculated temperature distribution, so it should be a useful basis for transient and residual stress calculations. These stress calculations are shown in Fig. 2 for selected ranges of depth somewhat below the bore surface; calculations very near the bore surface have little meaning due to the lack of information on material properties at the temperatures in this region. The significant region of tensile residual stress up to about $0.38 \mathrm{~mm}$ below the bore surface is alarming, considering the presence of hydrogen and the susceptibility of high strength cannon steel to hydrogen cracking.

\section{Residual Stress Effects on Fatigue Life and Yielding}

Fatigue lives calculated using the FIF concept for typical cannon conditions are shown in Fig. 3 for a range of

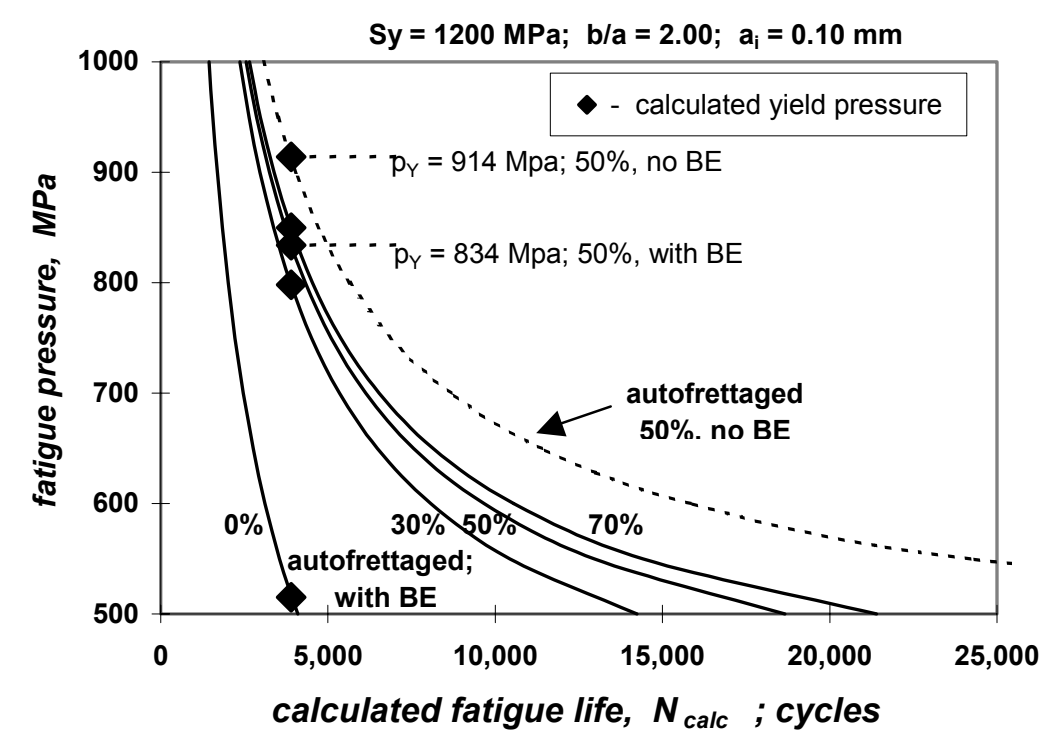

Figure 3: Life and yield pressure for various \% autofrettage fatigue pressure and various autofrettage conditions. Yield pressures for the cannon tube calculated from Eq. 5 are also shown. The results for $0 \%$ autofrettage, with the drastically lower lives and yield pressure, show how critical the autofrettage process is for cannon pressure vessels and similar high strength steel vessels. The lives and yield pressures for $30 \%, 50 \%$ and $70 \%$ autofrettage include the Bauschinger effect (BE) and show increases for increased autofrettage, but noticeably smaller increases in life and yield pressure are evident for additional autofrettage above about 50\%. This diminishing return is a direct consequence of the progressive decrease in effective yield strength in steel vessels that accompanies an increase in degree of autofrettage. When the Bauschinger effect is not included in the calculation of fatigue life, such as the dashed curve example in Fig. 3, the decrease in yield strength is not accounted for, and dangerously non-conservative calculations of fatigue life and yield pressure are produced.

Fatigue life and yield pressure calculations of a similar type to those of Fig. 3, but for actual cannon conditions, are shown in Fig. 4, typical of the chamber area of a tank cannon, with a b/a $=1.97,60 \%$ autofrettage, and $\mathrm{a}_{\mathrm{i}}=$ $0.10 \mathrm{~mm}$. In contrast to the diminishing effect of \% autofrettage in Fig. 3, there is no diminishing effect of increases in yield strength on either life or yield pressure. For the same degree of autofrettage, and thus the

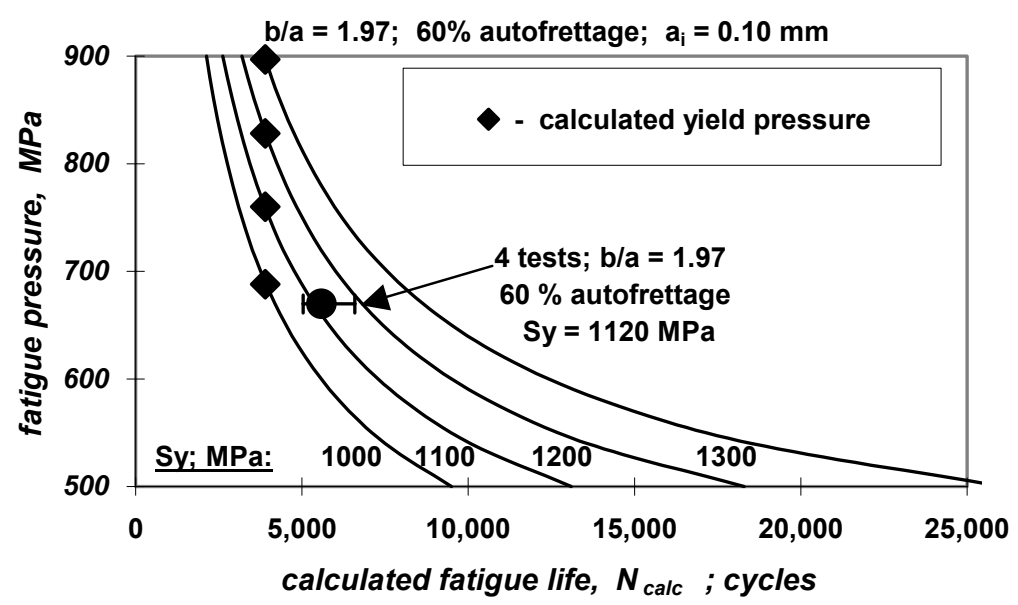

Figure 4: Life and yield pressure for various yield strengths same relative reduction in effective yield strength by the Bauschinger effect, increases in material yield strength are rewarded with significant increases in life and yield pressure (but at the expense of decreased resistance to fast and environmental cracking). Results from one of the groups of cannon fatigue tests described earlier are also shown in Fig. 4 , plotted at the $670 \mathrm{MPa}$ pressure used in the tests and the mean and range of fatigue life from the tests. These results provide a good verification of the methods of life calculation described in the work here, because the mean life from the tests falls very close to the correct position, just to the right of the $S_{Y}=$ $1100 \mathrm{MPa}$ curve, as would be expected for the $1120 \mathrm{MPa}$ mean yield strength of the tests. The test results also show, by their close proximity to the yield pressure for $\mathrm{S}_{\mathrm{Y}}=1000 \mathrm{MPa}$, that the $670 \mathrm{MPa}$ fatigue pressure for the tests was close to the yield pressure. 
The effects of both mechanically induced autofrettage residual stress and thermally induced firing residual stresses on fatigue life are considered in the results of Fig. 5. The solid curve shows the close agreement between the fatigue tests and the life calculations, when the nominal initial crack size is used, $\mathrm{a}_{\mathrm{i}}=0.10 \mathrm{~mm}$, which includes no effects of thermal residual stress. The dashed curves show the effects of two degrees of thermally induced residual stress, corresponding to two gas temperatures. Finite difference and mechanics

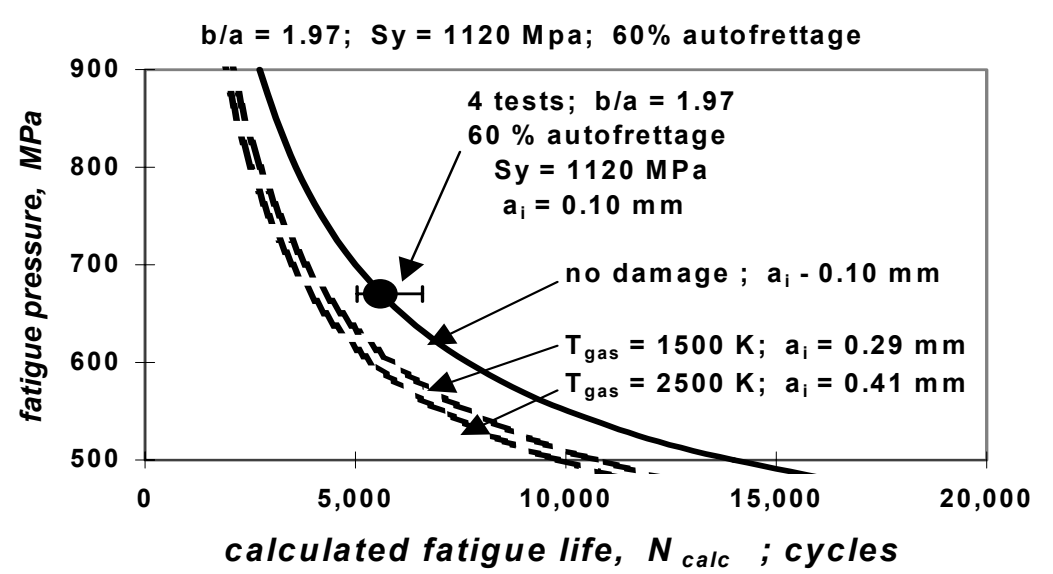

Figure 5: Life calculations with $B E$ for various $T_{G A S}$ and $a_{i}$ calculations were performed in the same manner as those that gave the results in Fig. 2, except that arbitrarily chosen values of $\mathrm{T}_{\text {gas }}, 1500 \mathrm{~K}$ and $2500 \mathrm{~K}$, were used to represent two levels of thermal damage. In these calculations, the maximum depths of the tensile residual stress were $0.29 \mathrm{~mm}$ and $0.41 \mathrm{~mm}$, respectively. Our experience is that hydrogen cracks will readily grow to the depth of the tensile residual stress, so a fatigue life analysis with $a_{i}$ values equal to these depths is appropriate. The result, at a $700 \mathrm{MPa}$ fatigue pressure for example, is a 5000 cycle life for $\mathrm{a}_{\mathrm{i}}=0.10 \mathrm{~mm}$ and a 3510 cycle life for $\mathrm{a}_{\mathrm{i}}=0.41 \mathrm{~mm}$. Thus, the thermal residual stresses produced by a $2500 \mathrm{~K}$ gas temperature would cause cracks that would reduce calculated fatigue life by $30 \%$, compared with the life with only autofrettage residual stress present.

\section{SUMMARY}

[i] Bauschinger-modified autofrettage residual stresses improve the fatigue intensity factor model for fatigue life of cannon pressure vessels, matching full-scale cannon fatigue test results with an $\mathrm{R}^{2}$ correlation of 0.92 . There is need for additional measurements and analysis of Bauschinger effect in other high strength steels used for pressure vessels, in addition to the Ni-Cr-Mo steel in the work here.

[ii] Thermally induced residual stress in a fired cannon has been modeled by finite difference calculations of temperature and mechanics calculations of transient thermal stress and residual stress. Temperature dependent properties are used, and temperature distributions are validated by direct comparison with the known temperatures and the observed depths of microstructural damage and transformations in fired cannons.

[iii] Calculations of pressure vessel fatigue life and yield pressure, incorporating Bauschinger modified residual stress, are presented for a range of applied pressure, diameter ratio, yield strength and \% autofrettage. Good agreement is demonstrated between calculations and measured lives from full-scale cannon fatigue tests. Significantly increased life is predicted for increases in yield strength and for $\%$ autofrettage up to about $50 \%$. [iv] The combined effects of mechanical autofrettage residual stress and thermal firing residual stress on cannon fatigue life are calculated, using a nominal initial crack size in association with autofrettage residual stress and larger crack sizes to account for added thermal residual stress. Hydrogen cracks can be expected to readily grow to the depth of the tensile thermal residual stress and thereby reduce the fatigue life.

\section{REFERENCES}

1. Milligan, R.V., Koo, W.H. and Davidson, T.E. (1966) Trans ASME, D, pp. 480-488.

2. Chaaban, A., Leung, K. and Burns, D.J. (1986) ASME Special Pub., PVP Vol 110, pp. 55-60.

3. Parker, A.P. (2001) Journal of Pressure Vessel Technology, Vol 123, to appear.

4. Underwood, J.H., Parker, A.P., Cote, P.J. and Sopok, S. (1999) Journal of Pressure Vessel Technology, Vol 121, pp. 116-120.

5. Underwood, J.H. and Parker, A.P. (1997) Advances in Fracture Research, Vol. 1, Pergamon, pp.215-226.

6. Incropera, F. P. and DeWitt, D. P. (1985) Introduction to Heat Transfer, Wiley, pp. 669-672.

7. Brown, W. F., Jr., Ed. (1970) Aerospace Structural Metals Handbook, Volume IIA, Non-Ferrous Alloys, Mechanical Properties Data Center, Traverse City, MI.

8. Smithells, C. J. (1962) Metals Reference Book, Butterworths, Washington. 